\title{
UMA ESCALA PARA MEDIR A INFRAESTRUTURA ESCOLAR
}

\author{
JOAQUIM JOSÉ SOARES NETO \\ GIRLENE RIBEIRO DE JESUS \\ CAMILA AKEMI KARINO \\ DALTON FRANCISCO DE ANDRADE
}

\section{RESUMO}

Promover a educação requer a garantia de um ambiente com condições para que a aprendizagem possa ocorrer. É importante proporcionar um ambiente físico, aqui denominado infraestrutura escolar, que estimule e viabilize o aprendizado, além de favorecer as interações humanas. Este artigo apresenta uma escala de infraestrutura escolar que foi construída utilizando como ferramenta a Teoria de Resposta ao Item e baseando-se em informações referentes às escolas obtidas no Censo Escolar da Educação Básica 2011. Foram estabelecidas quatro categorias: Elementar, Básica, Adequada e Avançada. Com base na escala, foi feita uma análise comparativa da infraestrutura escolar por região do país e por dependência administrativa. Acreditamos que os resultados obtidos podem ser úteis para orientar as políticas públicas de educação e para fundamentar estudos futuros sobre o impacto das condições materiais das escolas na qualidade do ensino. 


\section{RESUMEN}

Promover la educación requiere garantizar un ambiente con condiciones para que ocurra el aprendizaje. Es importante proporcionar un ambiente físico, denominado aquí infraestructura escolar, que estimule o viabilice el aprendizaje, además de promover las interacciones humanas. Este artículo presenta una escala de infraestructura escolar que se construyó utilizando como herramienta la Teoría de Respuesta al Ítem y teniendo como base las informaciones referentes a las escuelas, recolectadas no Censo de la Educación Escolar Básica de 2011. Se establecieron cuatro categorías: Elemental, Básica, Adecuada y Avanzada. Basándose en la escala, se ha efectuado uno análisis comparativo da infraestructura escolar por región y por dependencia administrativa. Creemos que los resultados obtenidos pueden ser útiles para orientar las políticas públicas de educación y para fundamentar estudios futuros sobre el impacto de las condiciones materiales de las escuelas en la calidad de la enseñanza.

PALABRAS CLAVE: TEORÍA DE RESPUESTA AL ÍTEM • ESCALA DE EVALUACIÓN・PROCESO ENSEÑANZA-APRENDIZAJE・ INFRAESTRUCTURA ESCOLAR.

\section{ABSTRACT}

To promote education requires ensuring an environment with conditions for learning to occur. It is important to provide a physical environment, here called the school infrastructure, or to make it possible to stimulate learning, besides providing human interactions. In this context, this paper aims to investigate the quality of the infrastructure of Brazilian schools. To that end, we developed a scale of school infrastructure, built using the Item Response Theory and based on data from the School Census of Basic Education 2011. From the scale, four categories were established for the infrastructure of schools: Elementary, Basic, Appropriate and Advanced. This paper makes a comparative analysis between the school infrastructure by region and administrative dependence. The results presented here also allow future studies about the impact of material conditions of schools on student learning.

KEYWORDS: ITEM RESPONSE THEORY • RATING SCALE • LEARNING PROCESSES・SCHOOL INFRASTRUCTURE. 


\section{INTRODUÇÃO}

A consolidação dos processos de avaliação educacional no Brasil tem levado ao aprofundamento de estudos sobre os fatores associados relevantes que possam explicar o desempenho escolar dos alunos nos exames padronizados. Entender esses fatores é de fundamental importância para o desenvolvimento de políticas públicas efetivas no campo da educação. Muitos estudos têm sido realizados para estabelecer quais desses fatores impactam o aprendizado dos alunos e em que proporção (BARBOSA; FERNANDES, 2001; JESUS; LAROS, 2004; LEE, 2008; RODRIGUES, 2002).

A infraestrutura das escolas é um dos aspectos da educação brasileira que vem chamando a atenção há muitos anos. Em meados de 1980, Castro e Fletcher (1986) discutem as condições materiais das escolas brasileiras na época. Eles colocam explicitamente a questão da eficiência e da eficácia dos gastos públicos com educação e falam da relevância da infraestrutura das escolas para o aprendizado dos alunos. Sátyro e Soares (2007) estudam a infraestrutura escolar com base nos dados dos Censos Escolares de 1997 a 2005 e constatam que, embora tenha ocorrido 
uma melhora no período, isso não repercutiu em termos da repetência e do aprendizado dos alunos. Outro fato mencionado é o das grandes diferenças existentes entre as escolas estaduais e privadas em relação às municipais que - como se verá neste artigo - persistem na atualidade. Os autores falam da necessidade de conhecer melhor o impacto das condições materiais das escolas nos resultados educacionais. Em outro trabalho, Soares, Razo e Fariñas (2006) incluem a infraestrutura escolar como fator importante para explicar os baixos resultados da educação na área rural.

No contexto internacional, Hattie (2009) trata da influência da infraestrutura no desempenho dos estudantes considerando vários países, entre os quais Estados Unidos e Nova Zelândia. Ele argumenta que a maior fonte de variância está, na verdade, dentro das escolas e não entre as escolas. Esse dado é consistente com países desenvolvidos, cuja infraestrutura escolar se apresenta de forma equitativa entre as escolas. Não obstante, tais achados não parecem ser ratificados em países que possuem um sistema educacional não equitativo.

É o caso do Brasil, por exemplo, onde a responsabilidade pela oferta da educação básica é dividida entre estados e municípios. Em um cenário de grandes desigualdades regionais e com a enorme disparidade existente entre as diversas redes de ensino, os estudos sobre fatores associados ao desempenho têm mostrado grandes diferenças entre as escolas (ALBERNAZ; FERREIRA; FRANCO, 2002; BARBOSA; FERNANDES, 2001; FLETCHER, 1998; JESUS; LAROS, 2004). Essas diferenças são explicadas por diversos fatores, entre eles, o nível socioeconômico das escolas.

Ainda no cenário internacional, em um estudo recente no contexto da América Latina, Duarte, Gargiulo e Moreno (2011) abordam o tema da infraestrutura e do aprendizado com base nos dados do Second Regional Comparative and Explanatory Study (Serce). Essa publicação traz uma série de referências de estudos feitos em outros países a respeito do tema.

Este artigo apresenta-se como uma contribuição para essa área de estudo ao oferecer uma escala para aferir a infraestrutura escolar. Nessa escala, cada escola brasileira tem uma "proficiência" em infraestrutura, e esse valor é interpretável, ou seja, cada escore nessa escala tem um significado prático e objetivo. Assim, podem-se categorizar as escolas em termos de suas estruturas 
materiais e, sobretudo, é possível levantar uma questão de fundamental importância: qual a infraestrutura adequada para que uma escola tenha condições de oferecer uma educação de melhor qualidade?

Além de contribuir para responder a essa questão de forma objetiva, a escala é útil com referência para estudos que tratam de fatores associados ao desempenho, pois o escore na escala de infraestrutura é um retrato mais preciso do nível socioeconômico da escola do que o nível socioeconômico médio dos alunos que a frequentam, medida usualmente utilizada para esse fim.

\section{METODOLOGIA}

O Censo Escolar da Educação Básica, realizado anualmente pelo Instituto Nacional de Estudos e Pesquisas Educacionais Anísio Teixeira (Inep), coleta dados sobre as escolas, turmas, docentes e alunos brasileiros. Os dados aqui utilizados foram extraídos do Censo Escolar 2011 e são provenientes do formulário Cadastro das Escolas, onde se reúnem informações sobre Caracterização/ Infraestrutura e Equipamentos.

Para a realização deste estudo, tivemos acesso a uma base de dados do Inep com 263.833 escolas, incluindo públicas e privadas, rurais e urbanas. Foram feitas filtragens nessa base, inicialmente por meio da variável Situação de Funcionamento, subdividida nos itens:

1. Em atividade

2. Paralisada

3. Extinta

4. Extinta no ano anterior

Foram consideradas apenas as escolas na situação Em Atividade. Após essa filtragem, a base ficou reduzida a 198.837 escolas.

Em seguida, foi considerada a variável Situação da Escola em RelaçãoaoCensoEscolar2011, conforme a seguinte classificação:

0. Escola não faltante (Censo 2011 fechado)

1. Escola faltante

2. Escola nova que não preencheu o Censo 2011

3. Escola com todas as matrículas não confirmadas 
4. Escola aberta (não encerrou o censo 2011)

5. Escola exclusiva de atendimento educacional especializado ou atendimento complementar (sem matrícula de escolarização)

Nesse caso, foram incluídas nas análises apenas as escolas na situação Escola não Faltante (Censo 2011 fechado), restando então 194.932 escolas.

Para caracterizar a infraestrutura, foram utilizados dois blocos de itens, Caracterização e Infraestrutura e Equipamentos, que englobam desde a variável 32 (Água consumida pelos alunos) até a variável 41d (Acesso à internet). Nesse intervalo, foram adotados alguns procedimentos, como descritos na sequência.

Em relação às variáveis 33 a 35 (Abastecimento de água, Abastecimento de energia elétrica, Esgoto sanitário) foi desconsiderada a qualidade mensurada no item e considerado apenas o atributo de existência, conforme o Quadro 1.

QUADRO 1 - Variáveis dicotomizadas para a montagem do banco de dados utilizado para a análise da Teoria da Resposta ao Item (TRI)

\begin{tabular}{|c|c|}
\hline & VARIÁVEL \\
\hline \multirow{3}{*}{33} & Abastecimento de água \\
\hline & O - Não existe \\
\hline & 1 - Existente \\
\hline \multirow{3}{*}{34} & Abastecimento de energia elétrica \\
\hline & O - Não existe \\
\hline & 1 - Existente \\
\hline \multirow{3}{*}{35} & Esgoto sanitário \\
\hline & O - Não existe \\
\hline & 1 - Existente \\
\hline
\end{tabular}

Fonte: Elaboração dos autores a partir do Censo Escolar da Educação Básica 2011.

Os itens "Quadra de esportes coberta" e "Quadra de esportes descoberta" foram transformados em apenas um item dicotômico: "Quadra de esportes coberta ou descoberta" 
(0 - Não existe e 1 - Existe). O mesmo tratamento foi dado para os itens "Sanitário fora do prédio" e "Sanitário dentro do prédio" que se tornaram: "Sanitário dentro ou fora do prédio" (0 - Não existe e 1 - Existe). Isso porque a intenção no momento era avaliar a existência ou não desses elementos da infraestrutura escolar, e não a qualidade deles.

Quanto aos itens excluídos da análise, o Quadro 2 apresenta os motivos da exclusão.

QUADRO 2 - Itens excluídos da análise da TRI e o motivo da exclusão

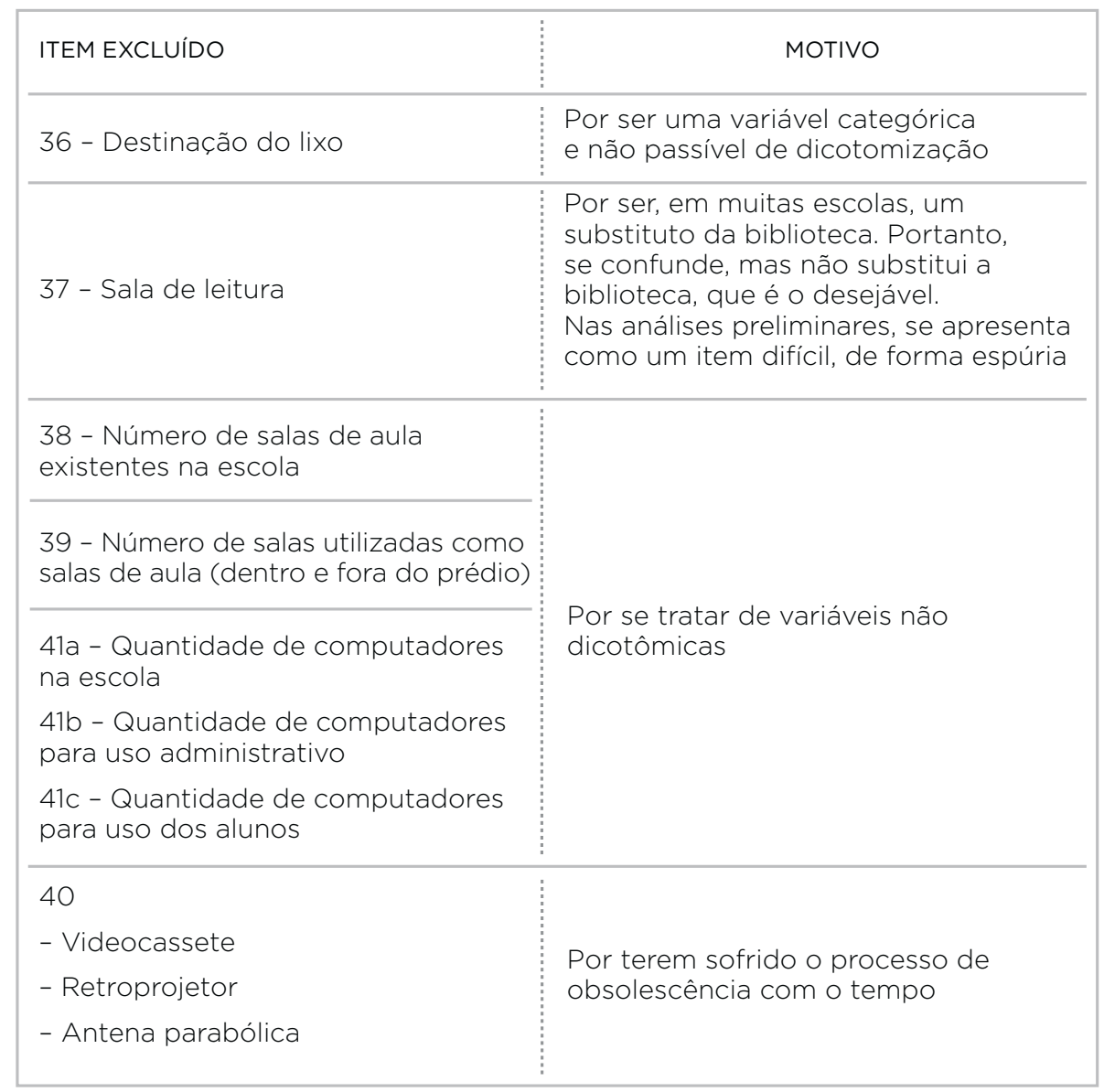

Fonte: Elaboração dos autores.

Alguns itens foram retirados das análises por não permitirem a dicotomização ou por exigirem um julgamento de valor relativo à quantidade no processo de dicotomização. Esse procedimento foi necessário devido à opção metodológica de se utilizar o modelo logístico dicotômico de dois parâmetros da Teoria da Resposta ao Item (TRI). As razões que subsidiaram a escolha desse modelo foram: 1) importância de se construir uma escala interpretável, o que é possível por meio da TRI; 2) o interesse 
inicial de construir uma escala que avalia a existência ou não de determinado elemento de infraestrutura, não sendo o foco, neste momento, a avaliação qualitativa desses elementos; 3) nas análises preliminares percebeu-se que, além de se posicionarem em pontos distintos da escala, os itens tinham níveis distintos de discriminação, ou seja, não contribuíam do mesmo modo na diferenciação das escolas.

Após todo o procedimento de filtragem, a base finalutilizada nas análises passou a contar com 24 itens referentes à infraestrutura escolar, descritos no Quadro 3.

QUADRO 3 - Itens utilizados nas análises da TRI

\begin{tabular}{|c|c|c|c|}
\hline ITEM & DESCRIÇÃO & ITEM & DESCRIÇÃO \\
\hline 1 & $\begin{array}{l}\text { Água consumida pelos } \\
\text { alunos }\end{array}$ & 13 & Parque infantil \\
\hline 2 & Abastecimento de água & 14 & Berçário \\
\hline 3 & $\begin{array}{l}\text { Abastecimento de } \\
\text { energia elétrica }\end{array}$ & 15 & $\begin{array}{l}\text { Sanitário fora ou dentro } \\
\text { do prédio }\end{array}$ \\
\hline 4 & Esgoto sanitário & 16 & Sanitário para educação infantil \\
\hline 5 & Sala de diretoria & 17 & Sanitário para deficientes físicos \\
\hline 6 & Sala de professor & 18 & $\begin{array}{l}\text { Dependências para deficientes } \\
\text { físicos }\end{array}$ \\
\hline 7 & $\begin{array}{l}\text { Laboratório } \\
\text { de informática }\end{array}$ & 19 & TV \\
\hline 8 & $\begin{array}{l}\text { Laboratório } \\
\text { de ciências }\end{array}$ & 20 & DVD \\
\hline 9 & $\begin{array}{l}\text { Sala de atendimento } \\
\text { especial }\end{array}$ & 21 & Copiadora \\
\hline 10 & $\begin{array}{l}\text { Quadra de esportes } \\
\text { coberta/descoberta }\end{array}$ & 22 & Impressora \\
\hline 11 & Cozinha & 23 & Computadores \\
\hline 12 & Biblioteca & 24 & Internet \\
\hline
\end{tabular}

Fonte: Elaboração dos autores. 


\section{ESCALA DE INFRAESTRUTURA}

Antes de iniciar as análises dos itens com base no modelo da TRI, as variáveis de infraestrutura do Censo Escolar foram analisadas conforme adequabilidade aos diversos segmentos de ensino (educação infantil, ensino fundamental e ensino médio) e por tipo de escola (pública ou particular). Essa análise foi necessária porque nem todos os segmentos de ensino exigem as mesmas condições de infraestrutura.

Assim, das 24 variáveis inicialmente consideradas, cinco foram submetidas a um tratamento diferenciado: parque infantil e sanitário de educação infantil - somente para as escolas que declararam ofertar esse nível de ensino; berçário-somente para escolas que ofertavam creche; laboratório de ciências - somente para as escolas que ofertavam ensino fundamental e médio; e cozinha - somente para as escolas públicas, uma vez que nelas a alimentação escolar é obrigatória. Para as escolas a que essas variáveis não se adequavam, elas foram tratadas nas análises pela TRI como "não se aplica".

Feito esse tratamento, realizou-se a primeira análise para estimação dos parâmetros dos itens, também conhecida como calibração. Foi utilizado o modelo logístico de dois parâmetros. Os resultados dessa análise indicaram dois itens com problemas de ajuste ao modelo da TRI: água filtrada e berçário, pois possuíam índices de discriminação muito baixos (parâmetro $a$ igual a 0,16 e 0,27 , respectivamente). Por esse motivo, essas variáveis foram desconsideradas e realizou-se uma segunda análise para reestimação dos parâmetros dos itens.

O Quadro 4 apresenta como resultado dessa segunda análise os 22 itens da escala de infraestrutura escolar com seus parâmetros de dificuldade $b$ e de discriminação $a$ na escala $(0,1)$, ou seja, escala com média de valor zero e desvio padrão de valor um. 
QUADRO 4 - Estimativas do parâmetro de discriminação e de dificuldade dos itens da escala de infraestrutura escolar, acompanhadas pelos respectivos erros padrões entre parênteses

\begin{tabular}{|c|c|c|c|}
\hline \multirow{2}{*}{ ITEM } & \multirow{2}{*}{ DESCRICCÃO } & \multicolumn{2}{|c|}{ PARÂMETRO } \\
\hline & & DISCRIMINAÇÃO & DIFICULDADE \\
\hline 1 & Água & $0,77(0,01)$ & $-2,99(0,02)$ \\
\hline 2 & Sanitário & $1,11(0,01)$ & $-2,34(0,01)$ \\
\hline 3 & Cozinha & $0,96(0,01)$ & $-2,28(0,01)$ \\
\hline 4 & Esgoto & $1,64(0,01)$ & $-1,93(0,01)$ \\
\hline 5 & Energia elétrica & $1,80(0,01)$ & $-1,88(0,01)$ \\
\hline 6 & TV & $3,02(0,02)$ & $-0,72(<0,00)$ \\
\hline 7 & DVD & $2,66(0,01)$ & $-0,62(<0,00)$ \\
\hline 8 & Sala de diretoria & $1,58(0,01)$ & $-0,55(<0,00)$ \\
\hline 9 & Computadores & $4,35(0,03)$ & $-0,46(<0,00)$ \\
\hline 10 & Impressora & $4,18(0,02)$ & $-0,34(<0,00)$ \\
\hline 11 & Internet & $2,70(0,01)$ & $0,00(<0,00)$ \\
\hline 12 & Sala de professores & $1,50(0,01)$ & $0,01(<0,00)$ \\
\hline 13 & Parque infantil & $1,34(0,01)$ & $0,19(<0,00)$ \\
\hline 14 & Laboratório de informática & $1,55(0,01)$ & $0,32(<0,00)$ \\
\hline 15 & Copiadora & $1,43(0,01)$ & $0,36(<0,00)$ \\
\hline 16 & $\begin{array}{l}\text { Sanitário para educação } \\
\text { infantil }\end{array}$ & $1,11(0,01)$ & $0,39(<0,00)$ \\
\hline 17 & Biblioteca & $1,32(0,01)$ & $0,56(<0,00)$ \\
\hline 18 & Quadra esportiva & $1,48(0,01)$ & $0,78(<0,00)$ \\
\hline 19 & $\begin{array}{l}\text { Sanitário para deficiente } \\
\text { físico }\end{array}$ & $1,14(0,01)$ & $1,14(<0,00)$ \\
\hline 20 & $\begin{array}{l}\text { Dependências para } \\
\text { deficiente físico }\end{array}$ & $1,12(0,01)$ & $1,26(<0,00)$ \\
\hline 21 & Laboratório de ciências & $1,51(0,01)$ & $1,43(<0,00)$ \\
\hline 22 & $\begin{array}{l}\text { Sala de atendimento } \\
\text { especial }\end{array}$ & $0,86(0,01)$ & $2,12(0,01)$ \\
\hline
\end{tabular}

Fonte: Elaboração dos autores.

A partir dessas estimativas, foram calculados os escores de infraestrutura escolar de todas as escolas da base do Censo 2011. Esses escores foram posteriormente transformados para uma escala com média 50 e desvio padrão 10. 
Tomando como referência os parâmetros dos itens, também é possível construir e analisar a curva de informação do teste em função da "proficiência" da escola na escala de infraestrutura, que é mostrada na Figura 1. Para cada ponto da escala, o erro de mensuração é o inverso do valor da informação. Assim, para cada ponto da escala, quanto maior é a informação, menor se configura o erro que está sendo cometido naquele ponto. Nota-se que escolas que possuem escores entre 40 e 60 são as que possuem estimativas mais precisas de suas proficiências na escala de infraestrutura, apresentando informação alta e erro de mensuração baixo. Já as escolas com escores abaixo de 40 ou acima de 60 possuem um erro de mensuração maior na estimação de suas proficiências. Esse erro maior deve-se a uma quantidade menor de itens nessas faixas da escala.

FIGURA 1 - Informação da escala de infraestrutura em relação ao valor da "proficiência" em infraestrutura

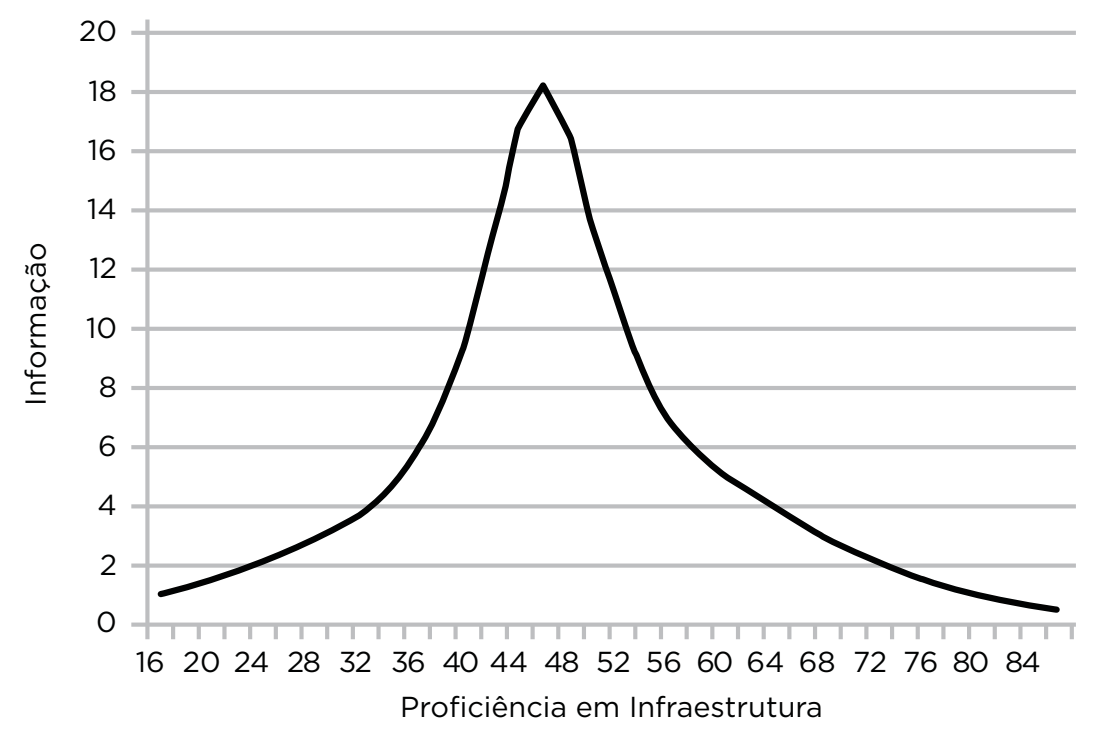

Fonte: Elaboração dos autores.

Em seguida, foram definidos os pontos âncoras da escala em intervalos de 10 unidades de medida da escala, incluindo a média da escala, 50. Para definir os itens âncora, foi considerado o percentual de resposta positiva empírica dos itens em torno de cada ponto âncora, tendo como base os respondentes (que no presente caso são as escolas respondentes do EducaCenso 2011) localizados meio desvio padrão acima e abaixo de cada ponto. 
Os itens âncoras são os que caracterizam os pontos da escala no sentido de que a maioria das escolas (mais de 65\%) situadas em cada um dos pontos responde positivamente ao item, enquanto menos da metade das escolas situadas no nível imediatamente inferior também responde positivamente, e a diferença entre os percentuais de acerto no ponto âncora e no ponto anterior é igual ou superior a $30 \%$.

Essa metodologia tem como base o estudo de Beaton e Allen (1992). Todos os itens da escala de infraestrutura escolar foram ancorados em algum ponto âncora, atendendo aos três critérios estabelecidos. Utilizamos aqui, para o estabelecimento dos itens âncoras, o percentual de resposta positiva empírica dos itens. A diferença entre a proporção empírica e a probabilidade do modelo da TRI é muito pequena. Só altera a posição de dois itens. Pela interpretação da escala, o posicionamento dado pela proporção empírica faz mais sentido do que o posicionamento do modelo da TRI. Em relação a esse ponto, segue-se aqui o mesmo critério do Sistema Nacional de Avaliação da Educação Básica (Saeb), que usa a proporção empírica.

Ainterpretação da escala evidenciou que as escolas podem ser classificadas em quatro grandes níveis de infraestrutura escolar: elementar, básica, adequada e avançada. No Quadro 5, éapresentada a descrição desses quatro níveis, assim como a porcentagem de escolas em cada intervalo de proficiência da escala. Os pontos de corte foram estabelecidos com base nas informações do questionário e na semelhança dos elementos de infraestrutura.

Chama a atenção, entre os resultados apresentados no Quadro 5, o fato de mais de 44\% das escolas da educação básica brasileira ainda apresentarem uma infraestrutura escolar elementar, apenas com água, sanitário, energia, esgoto e cozinha. Trata-se de aspectos sine qua non para o funcionamento de um prédio escolar, sem qualquer característica específica relacionada ao processo ensino-aprendizado.

Outro fato que chama a atenção é que somente $0,6 \%$ das escolas apresentam uma infraestrutura considerada avançada. Esses resultados demonstram o quanto ainda é preciso avançar para proporcionar aos estudantes um ambiente escolar com infraestrutura adequada aos propósitos de uma educação de qualidade, especialmente pública, o que perpassa pela qualidade da infraestrutura escolar. 


\section{QUADRO 5 - Descrição dos níveis da escala de infraestrutura escolar e a porcentagem de escolas por intervalo de proficiência}

\begin{tabular}{|c|c|c|c|}
\hline NÍVEL & INTERVALO & PORCENTAGEM & $\begin{array}{l}\text { DESCRIÇÃO DOS NÍVEIS } \\
\text { DE INFRAESTRUTURA }\end{array}$ \\
\hline 1 - Elementar & $\begin{array}{l}0<20 \\
20<30 \\
30<40 \\
40<50\end{array}$ & $\begin{array}{l}0,0 \\
2,8 \\
17,8 \\
23,9\end{array}$ & $\begin{array}{l}\text { Estão neste nível escolas } \\
\text { que possuem somente } \\
\text { aspectos de infraestrutura } \\
\text { elementares para o } \\
\text { funcionamento de uma } \\
\text { escola, tais como água, } \\
\text { sanitário, energia, esgoto } \\
\text { e cozinha }\end{array}$ \\
\hline 2 - Básica & $56<60$ & 40,0 & $\begin{array}{l}\text { Além dos itens } \\
\text { presentes no nível } \\
\text { anterior, neste nível as } \\
\text { escolas já possuem uma } \\
\text { infraestrutura básica, } \\
\text { típica de unidades } \\
\text { escolares. Em geral, elas } \\
\text { possuem: sala de diretoria } \\
\text { e equipamentos como TV, } \\
\text { DVD, computadores } \\
\text { e impressora }\end{array}$ \\
\hline 3 - Adequada & $60<70$ & 14,9 & $\begin{array}{l}\text { Além dos itens presentes } \\
\text { nos níveis anteriores, } \\
\text { as escolas deste nível, } \\
\text { em geral, possuem } \\
\text { uma infraestrutura mais } \\
\text { completa, o que permite um } \\
\text { ambiente mais propício para } \\
\text { o ensino e aprendizagem. } \\
\text { Essas escolas possuem, por } \\
\text { exemplo, espaços como sala } \\
\text { de professores, biblioteca, } \\
\text { laboratório de informática } \\
\text { e sanitário para educação } \\
\text { infantil. Há também espaços } \\
\text { que permitem o convício } \\
\text { social e o desenvolvimento } \\
\text { motor, tais como quadra } \\
\text { esportiva e parque infantil. } \\
\text { Além disso, são escolas que } \\
\text { possuem equipamentos } \\
\text { complementares como } \\
\text { copiadora e acesso } \\
\text { à internet }\end{array}$ \\
\hline 4 - Avançada & $\begin{array}{l}70<80 \\
>=80\end{array}$ & 0,6 & $\begin{array}{l}\text { As escolas neste nível, além } \\
\text { dos itens presentes nos } \\
\text { níveis anteriores, possuem } \\
\text { uma infraestrutura escolar } \\
\text { mais robusta e mais } \\
\text { próxima do ideal, com a } \\
\text { presença de laboratório de } \\
\text { ciências e dependências } \\
\text { adequadas para } \\
\text { atender estudantes com } \\
\text { necessidades especiais }\end{array}$ \\
\hline
\end{tabular}

Fonte: Elaboração dos autores. 


\section{APLICAÇÕES DA ESCALA}

Nesta seção, oferecem-se aplicações importantes da escala de infraestrutura escolar para realizar análises das características das escolas brasileiras. Primeiramente, são apresentadas algumas análises descritivas da distribuição das 194.932 escolas analisadas neste trabalho. Como pode ser visto na Figura 2, o intervalo da escala que contém escolas vai de 22,61 a 72,34. Os picos altos demonstram que existe um grande número de escolas com infraestruturas similares. Para se ter uma visão mais detalhada das condições dessas escolas, será necessário aumentar a quantidade de itens no EducaCenso para que se possa ter uma maior discriminação das escolas em termos de suas infraestruturas.

FIGURA 2 - Distribuição das escolas em relação à escala de infraestrutura

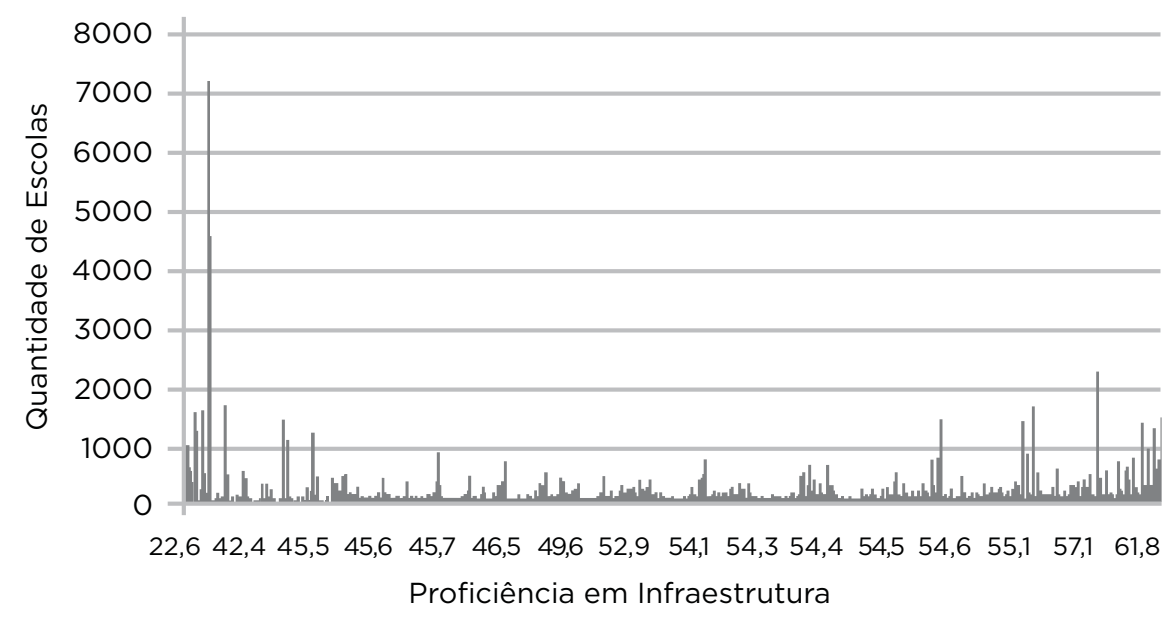

Fonte: Elaboração dos autores.

A Tabela 1 mostra em termos absoluto e relativo a distribuição das escolas nos intervalos e nos níveis da escala. No intervalo que inclui as escolas com infraestrutura entre os valores 50 e 60 encontram-se $40 \%$ das escolas, ou seja, aquelas que foram classificadas como tendo infraestrutura básica. Essas escolas têm as seguintes características gerais: dispõem de água, sanitário, energia, esgoto, cozinha, sala de diretoria e equipamentos como TV, DVD, computadores e impressora.

Apenas $15,5 \%$ das escolas brasileiras têm características mais sofisticadas que essas, ou seja, as escolas classificadas como tendo infraestrutura escolar adequada e avançada. 
TABELA 1 - Distribuição do número de escolas nos intervalos e níveis da escala de infraestrutura

\begin{tabular}{|c|c|c|c|c|}
\hline INTERVALOS & NÚMERO & PORCENTUAL & $\begin{array}{l}\text { PORCENTAGEM } \\
\text { ACUMULADA }\end{array}$ & $\begin{array}{c}\text { NÍVEL DE } \\
\text { INFRAESTRUTURA }\end{array}$ \\
\hline $20<30$ & 5.496 & 2,8 & 2,8 & \multirow{3}{*}{ Elementar } \\
\hline $30<40$ & 34.649 & 17,8 & 20,6 & \\
\hline $40<50$ & 46.594 & 23,9 & 44,5 & \\
\hline $50<60$ & 78.047 & 40,0 & 84,5 & Básica \\
\hline $60<70$ & 29.026 & 14,9 & 99,4 & Adequada \\
\hline $70<80$ & 1.120 & 0,6 & 100,0 & Avançada \\
\hline
\end{tabular}

Fonte: Elaboração dos autores.

Na Tabela 2 são apresentados o número e a porcentagem das escolas, em cada um dos níveis da escala para as regiões geográficas brasileiras. Observa-se que, do total de 24.079 escolas localizadas na Região Norte, 17.090 (71\%) estão no nível de infraestrutura elementar. Das escolas localizadas na Região Nordeste, a porcentagem de escolas no nível elementar é de $65 \%$. Nas outras três regiões, a maior porcentagem de escolas está no nível básico. Para qualquer uma das regiões, a porcentagem de escolas no nível avançado é sempre menor que $2 \%$.

TABELA 2 - Distribuição do número de escolas por nível da escala de infraestrutura escolar para cada região geográfica do país

\begin{tabular}{|c|c|c|c|c|c|c|c|c|c|}
\hline \multirow{3}{*}{$\begin{array}{l}\text { REGIÕES } \\
\text { Norte }\end{array}$} & \multicolumn{8}{|c|}{ INFRAESTRUTURA ESCOLAR } & \multirow{3}{*}{$\begin{array}{l}\text { TOTAL } \\
24.079\end{array}$} \\
\hline & \multicolumn{2}{|c|}{ ELEMENTAR } & \multicolumn{2}{|c|}{ BÁSICA } & \multicolumn{2}{|c|}{ ADEQUADA } & \multicolumn{2}{|c|}{ AVANCCADA } & \\
\hline & 17.090 & $71,0 \%$ & 5.353 & $22,2 \%$ & 1.565 & $6,5 \%$ & 71 & $0,3 \%$ & \\
\hline Nordeste & 49.338 & $65,1 \%$ & 20.912 & $27,6 \%$ & 5.376 & $7,1 \%$ & 205 & $0,3 \%$ & 75.831 \\
\hline Centro-oeste & 1.755 & $17,6 \%$ & 5.137 & $51,6 \%$ & 2.954 & $29,7 \%$ & 102 & $1,0 \%$ & 9.948 \\
\hline Sudeste & 13.478 & $22,7 \%$ & 33.826 & $57,0 \%$ & 11.738 & $19,8 \%$ & 322 & $0,5 \%$ & 59.364 \\
\hline Sul & 5.078 & $19,8 \%$ & 12.819 & $49,9 \%$ & 7.393 & $28,8 \%$ & 420 & $1,6 \%$ & 25.710 \\
\hline Total & 86.739 & $44,5 \%$ & 78.047 & $40,0 \%$ & 29.026 & $14,9 \%$ & 1.120 & $0,6 \%$ & 194.932 \\
\hline
\end{tabular}

Fonte: Elaboração dos autores. 
A seguir, utiliza-se a escala para analisar a distribuição das escolas nas categorias de infraestrutura em relação à dependência administrativa, ou seja, escolas federais, estaduais, municipais ou privadas. A Tabela 3 mostra em detalhes os resultados. Aqui, serão destacados apenas alguns dados da situação das escolas em relação à dependência administrativa.

Observa-se que $62,5 \%$ das escolas federais estão nas categorias Adequada e Avançada, 51,3\% das escolas estaduais estão na categoria Básica, 61,8\% das escolas municipais estão na categoria Elementar e 72,3\% das escolas privadas estão nas categorias Elementar e Básica. Nota-se também que das 5.496 escolas que se encontram no intervalo de 20 a 30 da escala, $5.036(99,9 \%)$ são municipais. 
TABELA 3 - Frequências, percentuais e percentuais acumulativos das escolas federais, estaduais, municipais e privadas em relação aos intervalos e níveis da escala de infraestrutura

\begin{tabular}{|c|c|c|c|c|c|}
\hline $\begin{array}{l}\text { DEPENDÊNCIA } \\
\text { ADMINISTRATIVA }\end{array}$ & INTERVALO & $\begin{array}{l}\text { NÚMERO DE } \\
\text { ESCOLAS }\end{array}$ & PORCENTAGEM & $\begin{array}{l}\text { PORCENTAGEM } \\
\text { ACUMULADA }\end{array}$ & $\begin{array}{c}\text { NÍVEL DE } \\
\text { INFRAESTRUTURA }\end{array}$ \\
\hline \multirow{5}{*}{ Federal } & $40 /-50$ & 23 & 5,1 & 5,1 & Elementar \\
\hline & $50 /-60$ & 146 & 32,4 & 37,5 & Básica \\
\hline & $60 /-70$ & 262 & 58,1 & 95,6 & Adequada \\
\hline & $70 /-80$ & 20 & 4,4 & 100,0 & Avançada \\
\hline & Total & 451 & 100,0 & & \\
\hline \multirow{7}{*}{ Estadual } & $20 /-30$ & 455 & 1,4 & 1,4 & \multirow{3}{*}{ Elementar } \\
\hline & $30 /-40$ & 1113 & 3,4 & 4,9 & \\
\hline & $40 /-50$ & 2854 & 8,8 & 13,7 & \\
\hline & $50 /-60$ & 16569 & 51,3 & 65,0 & Básica \\
\hline & $60 /-70$ & 10772 & 33,3 & 98,3 & Adequada \\
\hline & $70 /-80$ & 553 & 1,7 & 100,0 & Avançada \\
\hline & Total & 32316 & 100,0 & & \\
\hline \multirow{7}{*}{ Municipal } & $20 /-30$ & 5036 & 4,0 & 4,0 & \multirow{3}{*}{ Elementar } \\
\hline & $30 /-40$ & 33277 & 26,7 & 30,7 & \\
\hline & $40 /-50$ & 38744 & 31,1 & 61,8 & \\
\hline & $50 /-60$ & 39416 & 31,6 & 93,5 & Básica \\
\hline & $60 /-70$ & 7915 & 6,4 & 99,8 & Adequada \\
\hline & $70 /-80$ & 226 & 0,2 & 100,0 & Avançada \\
\hline & Total & 124614 & 100,0 & & \\
\hline \multirow{7}{*}{ Privada } & $20 /-30$ & 5 & 0,0 & 0,0 & \multirow{3}{*}{ Elementar } \\
\hline & $30 /-40$ & 259 & 0,7 & 0,7 & \\
\hline & $40 /-50$ & 4973 & 13,2 & 13,9 & \\
\hline & $50 /-60$ & 21916 & 58,4 & 72,3 & Básica \\
\hline & $60 /-70$ & 10077 & 26,8 & 99,1 & Adequada \\
\hline & $70 /-80$ & 321 & 0,9 & 100,0 & Avançada \\
\hline & Total & 37551 & 100,0 & & \\
\hline
\end{tabular}

Fonte: Elaboração dos autores. 
Finalmente, a Tabela 4 apresenta detalhadamente a distribuição das escolas na escala em relação à sua localização em áreas urbanas ou rurais. Enquanto que apenas $18,3 \%$ das escolas urbanas têm infraestrutura elementar, o oposto ocorre em relação às escolas rurais: $85,2 \%$ encontram-se nesta categoria.

TABELA 4 - Distribuição do número de escolas nos intervalos e níveis da escala de infraestrutura, segundo a localização

\begin{tabular}{|c|c|c|c|c|c|}
\hline LOCALIZAÇÃO & INTERVALO & $\begin{array}{l}\text { NÚMERO DE } \\
\text { ESCOLAS }\end{array}$ & PORCENTAGEM & $\begin{array}{l}\text { PORCENTAGEM } \\
\text { ACUMULADA }\end{array}$ & $\begin{array}{c}\text { NÍVEL DE } \\
\text { INFRAESTRUTURA }\end{array}$ \\
\hline \multirow{7}{*}{ Urbana } & $20 /-30$ & 13 & 0,0 & 0,0 & \multirow{3}{*}{ Elementar } \\
\hline & $30 /-40$ & 1674 & 1,4 & 1,4 & \\
\hline & $40 /-50$ & 20013 & 16,9 & 18,3 & \\
\hline & $50 /-60$ & 67788 & 57,2 & 75,5 & Básica \\
\hline & $60 /-70$ & 28014 & 23,6 & 99,1 & Adequada \\
\hline & $70 /-80$ & 1096 & 0,9 & 100,0 & Avançada \\
\hline & Total & 118598 & 100,0 & & \\
\hline \multirow{7}{*}{ Rural } & $20 /-30$ & 5483 & 7,2 & 7,2 & \multirow{3}{*}{ Elementar } \\
\hline & $30 /-40$ & 32975 & 43,2 & 50,4 & \\
\hline & $40 /-50$ & 26581 & 34,8 & 85,2 & \\
\hline & $50 /-60$ & 10259 & 13,4 & 98,6 & Básica \\
\hline & $60 /-70$ & 1012 & 1,3 & 100,0 & Adequada \\
\hline & $70 /-80$ & 24 & 0,0 & 100,0 & Avançada \\
\hline & Total & 76334 & 100,0 & & \\
\hline
\end{tabular}

Fonte: Elaboração dos autores. 


\section{CONCLUSÕES E SUGESTÕES}

O presente estudo apresenta-se como uma inovação para a área de avaliação da infraestrutura escolar no cenário nacional, pois, além de fazer uso de uma metodologia moderna de análise, a TRI estabelece uma escala de infraestrutura escolar com quatro níveis simples e objetivos.

A grande vantagem da escala aqui apresentada se deve ao fato de poder ser interpretada. Ademais, ela posiciona os itens segundo seu grau de dificuldade. Como um exemplo do poder de uma escala, está a possibilidade de se estabelecerem níveis que, por sua vez, permitem análises como as que mostram a grande desigualdade existente entre as escolas brasileiras, especialmente entre as zonas urbana e rural e entre as regiões Norte e Nordeste e o restante do país.

Em um estudo realizado por Oliveira e Laros (2007), que teve como objetivo identificar os construtos mensurados no questionário do Censo Escolar 2002 referente ao ensino fundamental com base no uso de análise fatorial, foi indicada a existência de dois fatores relacionados à infraestrutura: um de infraestrutura escolar e tecnológica e outro de infraestrutura básica e alimentar. O primeiro é descrito com variáveis como: quantidade média de computadores por aluno, existência de laboratório de informática, impressora, quadra de esporte, existência de merenda escolar, existência de laboratórios.

Os autores identificaram ainda que as escolas que possuíam os itens indicados nesse fator eram tipicamente da zona urbana e dispunham de recursos mais sofisticados para oferecer aos seus alunos. Ou seja, os autores referem-se a esse fator como indicador indireto da riqueza da escola. No que tange ao fator de infraestrutura básica e alimentar, há dois grupos de itens: os de infraestrutura básica, tais como energia pública, sanitários, coleta pública de lixo e água pública; e os itens relacionados ao fornecimento de alimento aos alunos, como geladeira, liquidificador, freezer, cozinha, depósito de alimentos e refeitório. Os dois fatores encontrados pelos autores citados podem ser parcialmente identificados na escala de infraestrutura do presente trabalho, sendo que a infraestrutura básica e alimentar corresponderia, sobretudo, ao nível elementar da escala deste estudo e a infraestrutura escolar e tecnológica estaria relacionada aos demais níveis. 
O estudo aqui publicado também chama a atenção para a importância e necessidade de se analisar, para além do desempenho dos estudantes, os fatores contextuais passíveis de intervenção que possam trazer melhorias para o sistema educacional. Assim, a escala de infraestrutura desenvolvida no trabalho pode contribuir para outros estudos que buscam avaliar o efeito escola e o impacto de fatores contextuais no desempenho escolar. Essas pesquisas contribuem para esclarecer o processo de produção de desigualdades e demonstram que as diferenças de desempenho podem ser a reprodução de um histórico de desigualdades sociais.

Por outro lado, deve-se considerar que essa é uma primeira proposta de escala de infraestrutura e que pode ainda ser melhorada. Por exemplo, uma das limitações é a quantidade de itens utilizada para a construção da escala. Quanto maior a quantidade de itens, maior a precisão da medida e informações mais confiáveis poderão ser disponibilizadas. Considerando a dificuldade de se coletar informações referentes a todas as escolas brasileiras, é importantíssimo o apoio do Censo Escolar nesse processo. Outra forma de ampliar o estudo do tema é avaliar não somente a existência dos elementos que compõem a infraestrutura escolar como água, esgoto, sala de professores, entre outros, mas também a qualidade desses elementos. Para a incorporação de outras informações, a utilização de outros modelos da TRI poderá ser necessária.

Por fim, ressalta-se a contribuição política e social deste estudo ao ressaltar as desigualdades de infraestrutura existentes entre as escolas. Este estudo demonstra o quanto o Brasil ainda está distante, não somente da equidade entre as escolas, mas também da garantia de um padrão mínimo de qualidade. Há um percentual alto de escolas que não possuem requisitos básicos de infraestrutura, como sala de diretoria, sala de professor e biblioteca. Assim, fica transparente a necessidade de políticas públicas que visem a diminuir as discrepâncias e promover condições escolares mínimas para que a aprendizagem possa ocorrer em um ambiente escolar mais favorável. 


\section{REFERÊNCIAS}

ALBERNAZ, Ângela; FERREIRA, Francisco H. G.; FRANCO, Creso. Qualidade e equidade na educação fundamental brasileira. Texto para Discussão $n^{\circ} 455$. Rio de Janeiro: PUC-Rio, 2002.

ANDRADE, Dalton F. de; TAVARES, Heliton R.; VALLE, Raquel da C. Teoria de Resposta ao Item: conceitos e aplicações. São Paulo: Associação Brasileira de Estatística - ABE, 2000.

BARBOSA, Maria Eugênia F.; FERNANDES, Cristiano. A escola brasileira faz diferença? Uma investigação dos efeitos da escola na proficiência em matemática dos alunos da 4 a série. In: FRANCO, Creso (Org.). Avaliação, ciclos e promoção na educação. Porto Alegre: Artmed, 2001. p. 121-153.

BEATON, Albert E.; ALLEN, Nancy L. Interpreting scales through scale anchoring. Journal of Educational Statistics, v. 17, p. 191-204, 1992.

BUCHMANN, C.; HANNUM, E. Education and stratification in developing countries: a review of theories and research. Review of Sociology, v. 27, p. 77-102, 2001.

CASTRO, Cláudio de Moura; FLETCHER, Philip. A escola que os brasileiros frequentaram em 1985. Rio de Janeiro: Ipea, Iplan,1986.

CERQUEIRA, C. A.; SAWYER, D. R. O. T. Tipologia dos estabelecimentos escolares brasileiros. Revista brasileira de Estudos Populacionais, São Paulo, v. 24, n. 1, p. 53-67, jan./jun. 2007.

DUARTE, Jesús; GARGIULO, Carlos; MORENO, Martín. School infrastructure and learning in Latin American elementary education: an analysis based on the Serce. Inter-American Development Bank, 2011.

FLETCHER, Philip R. À procura do ensino eficaz. Relatório técnico.

Departamento de Avaliação da Educação Básica. Brasília: MEC-Daeb, 1998.

HATTIE, John. Visible learning. A synthesis of over 800 meta-analyses relating to achievement. London and New York: Routledge, Taylor \& Francis Group, 2009.

JESUS, Girlene Ribeiro de; Laros, Jacob Arie. Eficácia escolar: regressão multinível com dados de avaliação em larga escala. Avaliação Psicológica, v. 3, n. 2. Porto Alegre, nov. 2004, p. 21-31.

KLEIN, R. Utilização da Teoria de Resposta ao Item no Sistema Nacional de Avaliação da Educação Básica (Saeb). Ensaio, Rio de Janeiro, v. 40, n. 11, p. 283-296, 2003.

LEE, V. L. Utilização de modelos lineares hierárquicos lineares para estudar contextos sociais: o caso dos efeitos da escola. In: BROOKE, Nigel; SOARES, José Francisco (Ed.). Pesquisa em eficácia escolar: origem e trajetórias. Belo Horizonte: Editora da UFMG, 2008. p. 273-296.

OLIVEIRA, Marcos Ruben de; LAROS, Jacob Arie. Construtos mensurados no Censo Escolar 2002 - Ensino Fundamental. Revista Electrónica Iberoamericana sobre Calidad, Eficacia y Cambio en Educación, v. 5, n. 2e, 2007.

RODRIGUES, Margarida Maria Mariana. Instrumentos de avaliação educacional: uma visão pedagógica e psicométrica integradas, estudo das provas do Saeb 
de Matemática $8^{a}$ série - 1997 e 1999. Dissertação (Mestrado em Psicologia) Instituto de Psicologia, Universidade de Brasília, Brasília. 2002.

SÁTYRO, Natália; SOARES, Sergei. A infra-estrutura das escolas brasileiras de ensino fundamental: um estudo com base nos censos escolares de 1997 a 2005. Textos para Discussão nº 1267. Brasília: Ipea, 2007.

SOARES, Sergei; RAZO, Renata; FARIÑAS, Mayte. Perfil estatístico da educação rural: origem socioeconômica desfavorecida, insumos escolares deficientes e resultados inaceitáveis. In: BOF, Alvana Maria (Org.). A educação no Brasil rural. Brasília: Instituto Nacional de Estudos e Pesquisas Educacionais Anísio Teixeira, 2006. p. 47-68.

JOAQUIM JOSÉ SOARES NETO

Professor doutor do Instituto de Física da Universidade de Brasília (IF/UnB). Membro do Programa de Pós-Graduação em Desenvolvimento, Sociedade e Cooperação Internacional do Centro de Estudos Avançados Multidisciplinares da Universidade de Brasília (Ceam/UnB) neto@unb.br

\section{GIRLENE RIBEIRO DE JESUS}

Professora doutora da Faculdade de Educação

da Universidade de Brasília (FE/UnB)

girlene@unb.br

\section{CAMILA AKEMI KARINO}

Professora doutora do Instituto de Psicologia da Universidade de Brasília (IP/UnB) camilaakarino@gmail.com

\section{DALTON FRANCISCO DE ANDRADE}

Professor doutor do Departamento de Informática e Estatística do Centro Tecnológico da Universidade Federal de Santa Catarina (INE/CTC/UFSC) dandrade@inf.ufsc.br 